\title{
Structure-Activity Relationship of 2-Arylquinolines as PET Imaging Tracers for Tau Pathology in Alzheimer Disease
}

\author{
Tetsuro Tago ${ }^{1,2}$, Shozo Furumoto ${ }^{1,2}$, Nobuyuki Okamura ${ }^{3}$, Ryuichi Harada ${ }^{4}$, Hajime Adachi ${ }^{1,2}$, Yoichi Ishikawa ${ }^{1}$, \\ Kazuhiko Yanai ${ }^{1,3}$, Ren Iwata ${ }^{1}$, and Yukitsuka Kudo ${ }^{4}$ \\ ${ }^{I}$ Division of Radiopharmaceutical Chemistry, Cyclotron and Radioisotope Center, Tohoku University, Sendai, Japan; ${ }^{2}$ Department of \\ Radiopharmaceutical Chemistry, Graduate School of Pharmaceutical Sciences, Tohoku University, Sendai, Japan; ${ }^{3}$ Department of \\ Pharmacology, Tohoku University School of Medicine, Sendai, Japan; and ${ }^{4}$ Division of Neuro-Imaging, Institute of Development, \\ Aging and Cancer, Sendai, Japan
}

Abnormal deposition of amyloid- $\beta$ and hyperphosphorylated tau protein in the brain are the pathologic hallmark of Alzheimer disease (AD). Noninvasive detection of the lesions is considered an effective tool for early diagnosis and staging of $A D$. In the past decade, we developed 2-arylquinoline (2-AQ) derivatives as PET tau tracers. In this study, we synthesized new derivatives and evaluated their properties. Methods: Fifteen 2-AQ derivatives were labeled with ${ }^{18} \mathrm{~F}$, and their binding to tau lesions was evaluated by autoradiography using $A D$ brain sections. The binding affinity for the $A D$ brain homogenates was assessed by an in vitro competitive binding assay with ${ }^{18} \mathrm{~F}-\mathrm{THK}-$ 5105. ${ }^{18} \mathrm{~F}$-labeled derivatives were injected into mice via the tail vein, and their pharmacokinetics over the first $120 \mathrm{~min}$ after injection were evaluated by an ex vivo biodistribution study. Tracer metabolism analysis was also assessed in mice. Results: The average $\log P$ value was 2.80 . This study revealed that $2-\mathrm{AQ}$ derivatives having ${ }^{18} \mathrm{~F}$-labeled side chains on benzene or position 7 of the quinoline showed significantly lower binding affinity for tau than 6-substituted quinoline derivatives. The $2-\mathrm{AQ}$ derivatives labeled with ${ }^{18} \mathrm{~F}$-fluoroethoxy, ${ }^{18} \mathrm{~F}$-fluoropropoxy, and ${ }^{18} \mathrm{~F}$-fluoro-polyethyleneglycol groups displayed slow clearance from blood or a high accumulation in bone, whereas derivatives labeled with the ${ }^{18} \mathrm{~F}$-(3-fluoro-2-hydroxy) propoxyl group did not. ${ }^{18} \mathrm{~F}-\mathrm{THK}-5151$ had outstanding tau binding properties and pharmacokinetics. Furthermore, the properties of its optically pure (S)-enantiomer (THK-5351) were superior to those of the $(R)$-enantiomer (THK-5451), particularly in terms of its clearance from the brain and its resistance to defluorination in mice. Conclusion: The structure-activity relationship study of $2-A Q$ derivatives revealed the optimal structural features for tau imaging agents. On the basis of these results, ${ }^{18} \mathrm{~F}-\mathrm{THK}-5351\left((\mathrm{~S})-{ }^{18} \mathrm{~F}-\mathrm{THK}-5151\right)$ was selected as a potential agent for tau imaging.

Key Words: Alzheimer's disease; positron emission tomography; tau proteins; structure-activity relationship

J Nucl Med 2016; 57:608-614

DOI: 10.2967/jnumed.115.166652

\footnotetext{
Received Sep. 28, 2015; revision accepted Nov. 29, 2015.

For correspondence or reprints contact: Shozo Furumoto, Cyclotron and Radioisotope Center (CYRIC), Tohoku University, 6-3 Aoba, Aramaki, Aoba-ku, Sendai 980-8578, Japan.

E-mail: furumoto@cyric.tohoku.ac.jp

Published online Dec. 23, 2015.

COPYRIGHT (c) 2016 by the Society of Nuclear Medicine and Molecular Imaging, Inc.
}

A tia, clinically characterized by memory impairment and affecting the activities of daily living. The typical pathologic hallmarks of $\mathrm{AD}$ are senile plaques and neurofibrillary tangles consisting of amyloid- $\beta(\mathrm{A} \beta)$ and hyperphosphorylated tau protein aggregates, respectively (1). In sporadic $\mathrm{AD}, \mathrm{A} \beta$ aggregates are thought to accumulate in the brain because of impaired clearance of $A \beta$ peptides. This process precedes the clinical manifestation of $\mathrm{AD}$ by more than a decade (2). Tau protein is a microtubule-associated protein and can be divided into 6 isoforms according to the number of microtubule-binding domains and the presence or absence of $2 \mathrm{~N}$-terminal inserts in the adult human brain (3). The behavior of tau is regulated by posttranslational modifications including phosphorylation and acetylation, and the number of phosphorylations per molecule is significantly greater in the brains of $\mathrm{AD}$ and other tauopathies than in healthy brains $(4,5)$. It is believed that these pathologic abnormalities precede brain atrophy and cognitive impairment (6); hence, they are regarded as targets for therapeutic intervention and diagnostic imaging of $\mathrm{AD}$.

During the last decade, several radiolabeled $A \beta$ binding probes were developed to visualize $\mathrm{A} \beta$ aggregates in $\mathrm{AD}$ brains by PET (7). The probes mainly consist of lipophilic heterocyclic rings, which allow them to cross the blood-brain barrier, and are labeled with ${ }^{11} \mathrm{C}$ or ${ }^{18} \mathrm{~F}$. Although ${ }^{11} \mathrm{C}$-Pittsburgh compound $\mathrm{B}$ is the most prevalent $\mathrm{A} \beta$ probe, $3{ }^{18} \mathrm{~F}$-labeled probes have already been approved by the Food and Drug Administration and the European Medicines Agency (8). The development of tau PET probes has been of increasing interest over the past few years (9). Tau PET imaging is expected to provide a better indication of the severity and prognosis of $\mathrm{AD}$ given the stronger association between neurodegeneration and tau pathology (10). Similar to $A \beta$ probes, most tau probes are small molecules radiolabeled with ${ }^{11} \mathrm{C}$ or ${ }^{18} \mathrm{~F}$ and have planar aromatic rings that enable them to bind to the $\beta$-sheet structure of tau aggregates. First-in-human PET studies in AD or other tauopathies of some tau probes have already been performed using novel tau tracers (11-13).

After screening more than 2,000 small molecules, we identified quinoline derivatives that could preferentially bind tau over $A \beta$ (14). Since then, we have been developing 2-arylquinoline (2-AQ) derivatives for tau PET imaging $(15-17)$ and $3{ }^{18} \mathrm{~F}$-labeled derivatives, ${ }^{18} \mathrm{~F}-\mathrm{THK}-523,{ }^{18} \mathrm{~F}-\mathrm{THK}-5105$, and ${ }^{18} \mathrm{~F}-\mathrm{THK}-5117$, have already been evaluated in clinical studies $(13,18,19)$. In recent basic and clinical studies, ${ }^{18} \mathrm{~F}-\mathrm{THK}-5117$ demonstrated high binding 
selectivity and affinity for tau over $\mathrm{A} \beta$ pathology and better pharmacokinetics in the living brain than other THK probes (18). However, ${ }^{18} \mathrm{~F}-\mathrm{THK}-5117$ showed marked white matter retention in both healthy controls and AD patients (18). Additionally, the white matter radioactivity might spill over and result in an overestimation of the radioactivity in the adjacent gray matter in which neurofibrillary tangles are located $(20,21)$. These observations prompted us to develop an optimized PET probe with lower background radioactivity in the brain than the existing probes. In this study, we performed a structure-activity relationship study of ${ }^{18} \mathrm{~F}$-labeled 2-AQ derivatives and evaluated their preclinical characteristics to determine their suitability as tau PET probes.

\section{MATERIALS AND METHODS}

\section{Synthesis of 2-AQ Derivatives}

Methods for the synthesis and characterization data of 2-AQ derivatives are described in the supplemental data (available at http:// jnm.snmjournals.org).

\section{Radiosynthesis of ${ }^{18} \mathrm{~F}-2-\mathrm{AQ}$ Derivatives}

A mixture of the corresponding precursor $(3 \mathrm{mg})$ and an activated ${ }^{18} \mathrm{~F}-\mathrm{KF}(1.7 \mathrm{GBq})$ and Kryptofix222 $(16 \mathrm{mg})$ in dimethyl sulfoxide was heated at $110^{\circ} \mathrm{C}$ for $10 \mathrm{~min}$. As necessary, $2 \mathrm{M} \mathrm{HCl}$ were then added and stirred for an additional $3 \mathrm{~min}$ to remove the tetrahydropyranyl group, followed by neutralization with $4 \mathrm{M} \mathrm{AcOK}$. The products were extracted with a Sep-Pak $\mathrm{tC}_{18}$ cartridge (Waters) and then purified by high-performance liquid chromatography (Inertsil ODS-4, $10 \times$ $250 \mathrm{~mm}, 5 \mu \mathrm{m}$ [GL Sciences, Inc.]; acetonitrile/20 mM NaH${ }_{2} \mathrm{PO}_{4}$ ). The radiolabeled product was isolated using a Sep-Pak $\mathrm{tC}_{18}$ cartridge from the high-performance liquid chromatography fraction. For the injectable, the product was solubilized in saline with polysorbate $80(<0.1 \%)$. The radiochemical purities of all ${ }^{18} \mathrm{~F}-2$-AQ derivatives were greater than $99 \%$. The radiochemical yields ranged from $11 \%$ to $72 \%$ (decay-corrected). The specific activities ranged from 16.1 to $118 \mathrm{GBq} / \mu \mathrm{mol}$.

\section{Log P Determination}

$\log P$ values were estimated by a reversed-phase high-performance liquid chromatography method as described in the supplemental data.

\section{In Vitro Autoradiography}

Experiments with human samples were performed under the regulations of the ethics committee of Tohoku University School of Medicine. Brain sections ( $8 \mu \mathrm{m}$, medial temporal lobe) from an $\mathrm{AD}$ patient (82-y-old woman) were incubated with each ${ }^{18} \mathrm{~F}-2-\mathrm{AQ}$ derivative $(0.22 \mathrm{MBq} / \mathrm{mL})$ for $10 \mathrm{~min}$ at room temperature and then washed with water and $50 \%$ ethanol. The sections were exposed to a BAS-III imaging plate (Fuji Film) overnight. Autoradiograms were obtained using a Typhoon FLA 9500 (GE Healthcare Bio-Sciences). Gallyas-Braak silver staining and anti-A $\beta$ immunostaining were performed with the adjacent sections (supplemental data).

\section{In Vitro Binding Assays}

According to the previous methods (16), the inhibitory constant $\left(\mathrm{K}_{\mathrm{i}}\right)$ and dissociation constant $\left(\mathrm{K}_{\mathrm{d}}\right)$ were determined using the $\mathrm{AD}$ brain homogenates of temporal gray matter and hippocampus, respectively. Details are described in the supplemental data.

\section{Biodistribution Assay in Control Mice}

Study protocols using animals were approved by the Institutional Animal Care and Use Committee of the Tohoku University Environmental and Safety Committee. Biodistribution assays in control mice were conducted by the method described in the supplemental data. In this study, a 2 min-to-10 min ratio of brain uptake was calculated and used as an index of the clearance rate of each ${ }^{18} \mathrm{~F}-2$-AQ derivative.

\section{Metabolite Analysis}

The ${ }^{18} \mathrm{~F}$-labeled tracer (18.5 MBq) was injected into male ICR mice ( 6 wk old; $n=3$ per group) via the tail vein. Mice were sacrificed by decapitation under anesthesia at 2,10 , and $30 \mathrm{~min}$ after injection, and the hemibrain and cardiac blood were collected. The plasma fractions were deproteinized with acetonitrile $(1: 1.5 \mathrm{v} / \mathrm{v})$ followed by centrifugation at $14,000 \mathrm{~g}$ for $5 \mathrm{~min}$ (extraction efficiency, $>94 \%$ ). Brain tissue homogenized with phosphate-buffered saline $(0.4 \mathrm{~mL})$ was also deproteinized with acetonitrile $(1 \mathrm{~mL})$ as described above (extraction efficiency, $>83 \%$ ). The supernatants were applied to a highperformance thin-layer chromatography silica gel $60 \mathrm{RP}-18 \mathrm{~W}$ plate (Merck KGaA), which was then developed with acetonitrile/20 mM $\mathrm{NaH}_{2} \mathrm{PO}_{4}$ (pH 6.5) (=1/1), dried, and exposed to a BAS-III imaging plate overnight. Autoradiograms were obtained and analyzed using a Typhoon FLA 9500 and Multi Gauge software (version 3.0; Fujifilm).

\section{RESULTS}

\section{Preparation of 2-AQ Derivatives}

We prepared 15 2-AQ derivatives for this structure-activity relationship study (Fig. 1). The fluoroalkoxylated and fluoropegylated derivatives and their tosylate precursors were synthesized via reactions of the corresponding side chains and 2-AQ frameworks (Supplemental Schemes 1 and 2). The 2-AQ framework was basically constructed by coupling quinoline triflate/chloride and phenylboronic/pyridinylboronic acid pinacol ester followed by a Mitsunobu reaction with a fluoro side chain (Supplemental Schemes 3-7). The frameworks of 2-(5-aminopyridin2-yl)quinoline derivatives were constructed by coupling 2-chloroquinoline and 2-(tributylstannyl)pyridine (Supplemental Schemes 8 and 9). The average molecular weight of the 2-AQ derivatives was 337.7 (282.31$398.47)$, and the average $\log P$ value was 2.80 (1.47-4.39) (Supplemental Table 1).

FIGURE 1. Chemical structures of ${ }^{18} \mathrm{~F}-2-\mathrm{AQ}$ derivatives. 
TABLE 1

Autoradiographic Characteristics and $\mathrm{K}_{\mathrm{i}}$ and $\mathrm{K}_{\mathrm{d}}$ Values of THK Compounds

\begin{tabular}{rccc}
\hline THK no. & Autoradiography (tau/A $\beta)$ & $\mathrm{K}_{\mathrm{i}}(\mathrm{nM})$ & $\mathrm{K}_{\mathrm{d}}(\mathrm{nM})$ \\
\hline 523 & $++/-$ & 183 & - \\
\hline 5377 & $++/-$ & 51.3 & - \\
5378 & $+/+$ & 87.2 & - \\
\hline 5140 & $++/+$ & 54.8 & - \\
\hline 5035 & $-/-$ & 98.4 & - \\
\hline 5156 & $-/-$ & $>1,000$ & - \\
\hline 5107 & $-/-$ & 142 & - \\
\hline 5116 & $-/-$ & 106 & - \\
\hline 5117 & $+++/-$ & 27.4 & 11.5 \\
\hline 5105 & $+++/+$ & 10.1 & 4.40 \\
\hline 5125 & $+/-$ & 28.0 & 10.2 \\
\hline 5151 & $+++/-$ & 29.1 & 7.07 \\
\hline 5129 & $++/+$ & 17.5 & 3.14 \\
\hline 5307 & $+/-$ & 83.5 & 5.60 \\
\hline 5287 & $++/-$ & 26.0 & 2.60 \\
\hline
\end{tabular}

Symbols indicate results of binding intensities semiquantitatively analyzed by ARG-based binding assay. - indicates no binding of compound to tau or $A \beta,+$ corresponds to weak binding, ++ corresponds to moderate binding, and +++ corresponds to strong binding.

\section{In Vitro Autoradiography}

In the autoradiography assay, we evaluated the binding characteristics of the ${ }^{18} \mathrm{~F}-2-\mathrm{AQ}$ derivatives for medial temporal lesions of the AD brain. The semiquantitative results are summarized in Table 1. Most derivatives with a side chain on position 6 of the quinoline showed tau-characteristic laminar distribution close to the boundary between the gray matter and white matter.



FIGURE 2. Autoradiograms of representative 2-arylquinoline derivatives and images of Gallyas-Braak staining and $A \beta$ immunostaining. (A) ${ }^{18} \mathrm{~F}-\mathrm{THK}-5117$. (B) ${ }^{18} \mathrm{~F}-\mathrm{THK}-5117+25 \mu \mathrm{M}$ THK-5117. (C) ${ }^{18} \mathrm{~F}-\mathrm{THK}-$ 5151. (D) ${ }^{18} \mathrm{~F}-\mathrm{THK}-5151+25 \mu \mathrm{M}$ THK-5151. (E) Gallyas-Braak staining. (F) $A \beta$ immunostaining.
Among them, ${ }^{18}$ F-THK-5117 and ${ }^{18}$ F-THK-5151 showed strong and highly selective binding for tau (Figs. 2A and 2C, respectively) and smaller amounts of nonspecific binding in white matter (Figs. 2B and 2D, respectively). A (3-fluoro-1-hydoxy)-2-propoxyl derivative ( ${ }^{18} \mathrm{~F}$-THK-5035) showed a weak binding to tau in the $\mathrm{AD}$ brain. Conversely, other derivatives with a side chain on position 7 of the quinoline $\left({ }^{18} \mathrm{~F}-\mathrm{THK}-5107\right)$ or benzene $\left({ }^{18} \mathrm{~F}-\mathrm{THK}-\right.$ 5156) did not show any binding to both tau and $A \beta$ lesions observed by Gallyas-Braak staining (Fig. 2E) and $A \beta$ immunostaining (Fig. 2F), respectively.

\section{In Vitro Binding to AD Brain Homogenate}

The binding affinity of 2-AQ derivatives was evaluated by saturation binding assays to determine their $\mathrm{K}_{\mathrm{d}}$ values or competitive binding assay with ${ }^{18} \mathrm{~F}$-THK-5105 using AD brain homogenate (Table 1). With the exception of THK-5116, the 6-subsituted quinoline (3-fluoro-2-hydroxy)-1-propoxy derivatives had lower $\mathrm{K}_{\mathrm{i}}$ values than other derivatives. All the derivatives that showed no binding to tau lesions in the autoradiography assay had $\mathrm{K}_{\mathrm{i}}$ values of more than approximately $100 \mathrm{nM}$. The $\mathrm{K}_{\mathrm{d}}$ values of the tested derivatives ranged from 2.60 to $11.5 \mathrm{nM}$. $N, N$-dimethylamino compounds tended to have lower $\mathrm{K}_{\mathrm{d}}$ values than their corresponding $\mathrm{N}$-methylamino derivatives, similar to the trend observed for the A $\beta$ probe (22).

\section{Biodistribution in Control Mice}

The pharmacokinetics of the ${ }^{18} \mathrm{~F}-2-\mathrm{AQ}$ derivatives were evaluated by ex vivo biodistribution assay, and the results are summarized in Table 2. All derivatives showed high initial brain uptake ranging from 2.72 percentage injected dose per gram $(\% \mathrm{ID} / \mathrm{g})$ to $9.20 \% \mathrm{ID} / \mathrm{g}$. Highly lipophilic ${ }^{18}$ F-THK-5378 and ${ }^{18} \mathrm{~F}-\mathrm{THK}-5035$ exhibited slower brain uptake with a peak at $10 \mathrm{~min}$ after injection, whereas the radioactivity in the brain of other derivatives decreased time-dependently after 2 min after injection. The highest three 2 min-to-10 min ratios of brain uptake were 3.6 for ${ }^{18} \mathrm{~F}$ THK-5151, 2.8 for ${ }^{18} \mathrm{~F}-\mathrm{THK}-5307$, and 2.2 for ${ }^{18} \mathrm{~F}-\mathrm{THK}-5117$ (16). Comparison of the radioactivity in blood and bone at $120 \mathrm{~min}$ after injection revealed that the structure of the side chain largely affects the pharmacokinetic characteristics of the radiotracer in mice. High blood radioactivity retention both decreases the signal-to-background ratio and increases bone accumulation due to defluorination of the ${ }^{18} \mathrm{~F}$-labeled radiotracer. The 2-AQ derivatives with either fluoropropoxyl or 3-fluorohydroxypropoxyl side chains showed low blood radioactivity $(0.22-0.77 \% \mathrm{ID} / \mathrm{g})$. By comparison, fluoroethoxyl and fluoropegylated derivatives demonstrated higher blood radioactivity of more than $1.5 \% \mathrm{ID} / \mathrm{g}$ at $120 \mathrm{~min}$ after injection. In the bone, the radioactivity accumulation of the fluoropropoxyl derivative (THK-5378) was the highest (15.5\% $\%$ ID/g) of all tested compounds and marked with THK5377 and THK-5140 (5.39 and $6.37 \% \mathrm{ID} / \mathrm{g}$, respectively). No noticeable accumulation in the bone was observed with the other derivatives.

\section{Evaluation of THK-5151 Enantiomers}

From the results of autoradiography and pharmacokinetic studies, we selected THK-5151 as the most promising candidate for tau PET imaging. THK-5151 has a chiral center in its side chain and thus has 2 optical isomers (Fig. 3A), and it was anticipated that the biologic activities would be different between the enantiomers (23). Therefore, we synthesized the THK-5151 enantiomers and evaluated their properties as tau imaging probes (Supplemental Schemes 10 and 11; Supplemental Fig. 1). The autoradiograms 
TABLE 2

Pharmacokinetic Properties of Compounds in Mice

\begin{tabular}{|c|c|c|c|c|c|c|c|c|}
\hline \multirow[b]{2}{*}{ THK no. } & \multicolumn{5}{|c|}{ Brain \%ID/g } & \multirow[b]{2}{*}{ Brain uptake ratio* } & \multirow[b]{2}{*}{ Blood \%ID/g at $120 \mathrm{~min}$} & \multirow[b]{2}{*}{ Bone $\% I D / g$ at $120 \mathrm{~min}$} \\
\hline & $2 \min$ & $10 \min$ & $30 \mathrm{~min}$ & $60 \min$ & $120 \mathrm{~min}$ & & & \\
\hline $523^{\star}$ & 2.72 & 2.12 & 1.47 & 1.46 & 1.34 & 1.3 & 1.78 & 2.09 \\
\hline 5377 & 4.33 & 3.98 & 2.01 & 1.33 & 1.25 & 1.1 & 1.56 & 5.39 \\
\hline 5378 & 3.83 & 4.29 & 2.55 & 1.72 & 0.95 & 0.89 & 0.23 & 15.5 \\
\hline 5140 & 5.83 & 2.72 & 1.30 & 1.22 & 1.20 & 2.1 & 1.63 & 6.37 \\
\hline 5035 & 6.01 & 6.17 & 2.83 & 1.32 & 0.72 & 0.97 & 0.77 & 2.96 \\
\hline 5156 & 5.70 & 3.58 & 0.93 & 0.26 & 0.13 & 1.6 & 0.23 & 0.33 \\
\hline 5107 & 5.60 & 3.56 & 1.05 & 0.47 & 0.34 & 1.6 & 0.53 & 1.52 \\
\hline 5116 & 3.36 & 1.61 & 0.75 & 0.57 & 0.51 & 2.1 & 0.59 & 2.56 \\
\hline $5117^{*}$ & 6.06 & 2.73 & 0.59 & 0.26 & 0.24 & 2.2 & 0.24 & 0.95 \\
\hline $5105^{\star}$ & 9.20 & 8.60 & 3.61 & 1.00 & 0.39 & 1.1 & 0.35 & 1.24 \\
\hline 5125 & 7.82 & 5.09 & 1.42 & 0.61 & 0.47 & 1.5 & 0.55 & 1.96 \\
\hline 5151 & 4.57 & 1.28 & 0.50 & 0.46 & 0.41 & 3.6 & 0.42 & 2.15 \\
\hline 5129 & 7.65 & 4.91 & 1.92 & 1.03 & 0.46 & 1.6 & 0.49 & 1.57 \\
\hline 5307 & 6.01 & 2.13 & 0.46 & 0.23 & 0.22 & 2.8 & 0.31 & 0.98 \\
\hline 5287 & 7.82 & 5.00 & 2.37 & 1.12 & 0.40 & 1.6 & 0.31 & 0.78 \\
\hline
\end{tabular}

of ${ }^{18} \mathrm{~F}$-THK-5151 enantiomers used to evaluate their binding properties were apparently indistinguishable from each other. The $\mathrm{K}_{\mathrm{d}}$ value for binding of the $(S)$-enantiomer $\left({ }^{18} \mathrm{~F}-\mathrm{THK}-5351,2.9 \mathrm{nM}\right)$ to $\mathrm{AD}$ brain homogenate was lower than that of the $(R)$-enantiomer $\left({ }^{18} \mathrm{~F}\right.$ THK-5451, $28 \mathrm{nM}$ ). Obvious differences were demonstrated in a pharmacokinetic study in mice (Figs. 3B and 3C). The (S)-enantiomer had a faster clearance from the brain and blood than ${ }^{18} \mathrm{~F}-\mathrm{THK}-5451$, and the brain uptake ratios after 10 min after injection of ${ }^{18} \mathrm{~F}-\mathrm{THK}-$ 5351 were much higher than those of ${ }^{18} \mathrm{~F}$-THK-5451 although the brain-to-blood ratios of both enantiomers were around 1.0 after 10 min after injection (Table 3). Furthermore, the bone radioac-

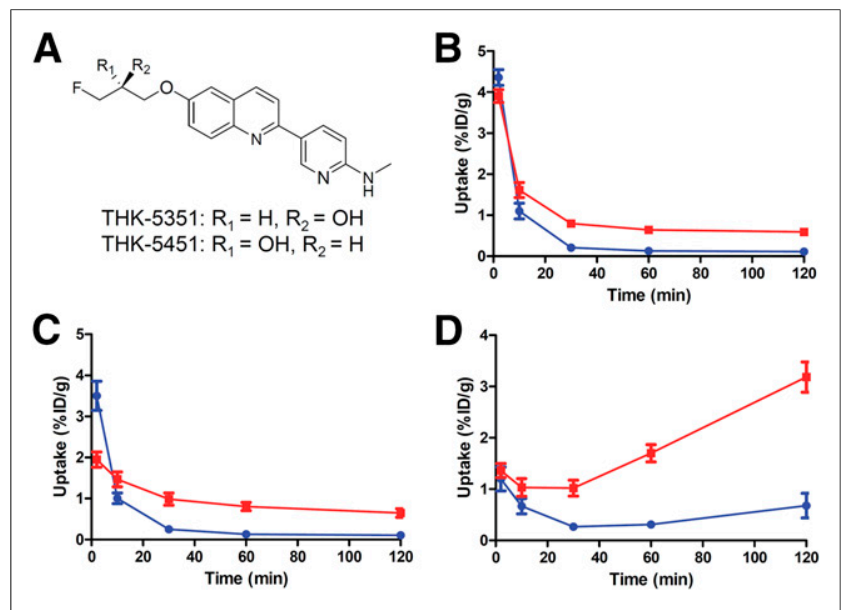

FIGURE 3. (A) Chemical structures of THK-5351 and THK-5451. (B-D) Time-activity curves of ${ }^{18} \mathrm{~F}-\mathrm{THK}-5351$ (blue) and ${ }^{18} \mathrm{~F}-\mathrm{THK}-5451$ (red) in mice brain (B), blood (C), and bone (D). tivity of ${ }^{18} \mathrm{~F}-\mathrm{THK}-5451$ was about 5 times higher than that of ${ }^{18} \mathrm{~F}-$ THK-5351 at $120 \mathrm{~min}$ after injection (Fig. 3D).

\section{Metabolite Analysis}

We analyzed the metabolism of ${ }^{18}$ F-THK-5351 and ${ }^{18} \mathrm{~F}-\mathrm{THK}-$ 5451 in control mouse brain and plasma. Time-activity curves of radiometabolites in brain and plasma are indicated in Figure 4. Both tracers gradually degraded in plasma after injection, and 2 prominent polar radiometabolites (M2 and M3 in Fig. 4) were observed. In the brain, degradation of both tracers was relatively slow compared with that in plasma, and the unchanged radiotracer decreased nearly $40 \%$ at $30 \mathrm{~min}$ after injection.

\section{DISCUSSION}

Previously, we demonstrated the potential of THK compounds to image AD tau pathology in a PET study, although visual PET image inspection was complicated as a result of the relatively high nonspecific binding of the compounds in white matter $(13,19)$. For further structural optimization of THK compounds, we synthesized 2-AQ derivatives including pyridine derivatives and evaluated the relationship between their structures and performance as a tau PET probe.

With respect to binding affinity, we assessed $K_{d}$ or $K_{i}$ values of the derivatives. Generally, the lower value meant higher binding affinity. The $\mathrm{K}_{\mathrm{d}}$ values of the (3-fluoro-2-hydroxy)-1-propoxy derivatives were below $20 \mathrm{nM}$, suggesting that the derivatives have sufficient binding affinity to be used as tau imaging probes (10). Compared with the $K_{d}$ values, the $K_{i}$ values were higher except that for THK-5105, and their variation may have been caused by differences in the binding sites between the inhibitors and ${ }^{18} \mathrm{~F}-\mathrm{THK}-5105$. Difference of $\mathrm{K}_{\mathrm{d}}$ values between enantiomers of ${ }^{18}$ F-THK-5151 was assumed to be caused by differences in binding kinetics as well as ${ }^{18}$ F-THK-5105 (24). 
TABLE 3

Pharmacokinetic Properties of ${ }^{18} \mathrm{~F}-\mathrm{THK}-5351$ and ${ }^{18} \mathrm{~F}-\mathrm{THK}-$ 5451 in Mice

\begin{tabular}{ccc}
\hline $\begin{array}{c}\text { Time after } \\
\text { injection (min) }\end{array}$ & Brain-to-blood ratio & Brain uptake ratio* \\
\hline 18 F-THK-5351 & & \\
10 & 1.1 & 4.0 \\
30 & 0.8 & 21 \\
60 & 1.0 & 33 \\
120 & 1.1 & 38 \\
\hline${ }^{18} \mathrm{~F}-\mathrm{THK}-5451$ & & \\
10 & 1.1 & 2.4 \\
\hline 30 & 0.8 & 4.9 \\
60 & 0.8 & 6.1 \\
120 & 0.9 & 6.6 \\
\hline
\end{tabular}

${ }^{*}$ Calculated as ratio of values at $2 \mathrm{~min}$ to those at each specified time.
The lipophilicity of the radiotracer is one of the primary factors that contributes to its pharmacokinetics in the brain. Ideally, a tau PET tracer should be cleared quickly from the brain to avoid prolongation of the time required to reach equilibrium in a PET study and to increase the signal-to-background ratio (10). Radiotracers need sufficient lipophilicity with $\log P$ values of $1-3$ to cross the blood-brain barrier; however, too high of a lipophilicity results in a high level of nonspecific binding and slow clearance from the brain $(22,25)$. Except for THK-523, the 2-AQ derivatives showed a common parabolic relationship between their $\log P$ values and brain uptake at $2 \mathrm{~min}$ after administration similar to what was observed in other studies (Fig. 5A) (22,25). Interestingly, 2 min-to-10 min ratios of brain uptake showed a linear negative correlation with $\log P$ values $(r=-0.72, P=0.0023$, Fig. 3B), whereas 2 min-to-30 min and $2 \mathrm{~min}-$ to-60 min ratios did not $(r=-0.60, P=0.017$, and $r=$ $-0.39, P=0.15$, respectively). These results suggest that a lower lipophilic derivative tends to exhibit faster washout from the brain in the early phase after administration, and $\log P$ value could be useful for estimating the brain kinetics of the early phase. In previous studies, 2 min-to-30 min or $2 \mathrm{~min}$-to-60 min ratios of brain uptake were used as an index of the tracer clearance $(16,22)$. In this study, however, the clearance rates of some highly lipophilic compounds with high brain uptake were overestimated when they were evaluated by a 2 min-to$60 \mathrm{~min}$ ratio. Additionally, the brain uptake of other test compounds with fast brain clearance, such as ${ }^{18} \mathrm{~F}-\mathrm{THK}-5129$, bottomed out by $30 \mathrm{~min}$ after injection; thus, their clearance rates were underestimated by a 2 min-to-30 min ratio. These results also support the use of a 2 min-to-10 $\mathrm{min}$ ratio as an index of the tracer clearance. Judging from the 2 min-to-10 min ratio, 2-/3-methylaminopyridine is a favorable partial structure of 2-AQ scaffold for rapid tracer clearance from the brain.

The effects of varying the ${ }^{18} \mathrm{~F}$-labeled side chains were prominently demonstrated in the biodistribution assay (Table 2). Previously, Pan et al. demonstrated that ${ }^{18} \mathrm{~F}$-2-fluoroethanol had slow clearance from major organs including the brain, and this phenomenon was believed to be caused by intracellular trapping of radiometabolites generated by oxidative metabolism $(26,27)$. By contrast, the radioactive clearance of ${ }^{18} \mathrm{~F}$-3-fluoropropanol was rapid, but remarkable bone accumulation was observed (26). Exactly the same trends as their study were observed in this study, suggesting the need for further optimization of these ${ }^{18} \mathrm{~F}$-labeling groups. Considering the results that (3-fluoro-2-hydroxy)-1-propoxy derivatives were commonly cleared from blood smoothly and only negligibly accumulated in bone, addition of the hydroxyl group to the fluoropropoxyl group could be an effective way to optimize the side chain. However, the modification raised a new issue concerning a chirality at the hydroxyl carbon.

$(S)$-enantiomer, ${ }^{18}$ F-THK-5351, showed faster kinetics in the brain and blood and 
TABLE 4

Summary of Representative THK Tau Probe Properties

\begin{tabular}{|c|c|c|c|}
\hline Property & ${ }^{18} \mathrm{~F}-\mathrm{THK}-5105$ & ${ }^{18} \mathrm{~F}-\mathrm{THK}-5117$ & ${ }^{18} \mathrm{~F}-\mathrm{THK}-5351$ \\
\hline Affinity $K_{d}(n M)$ & 4.4 & 11.5 & 2.9 \\
\hline Selectivity tau/A $\beta$ & $+++/+$ & $+++/-$ & $+++/-$ \\
\hline Lipophilicity $\log P$ & 2.97 & 2.17 & 1.49 \\
\hline Brain kinetics (2 min-to-10 min ratio) & 1.1 & 2.2 & 4 \\
\hline Half-life of cerebellum SUV* (min) & $40-50$ & 20-30 & $10-20$ \\
\hline References & Okamura et al. (13) & Harada et al. (18) & Harada et al. (32) \\
\hline \multicolumn{4}{|c|}{$\begin{array}{l}\text { *Half-life of peak SUV of cerebellum was estimated from time-activity curves in literature. } \\
\text { Symbols indicate results of binding intensities semiquantitatively analyzed by ARG-based binding assay. - indicates no binding } \\
\text { compound to tau or } A \beta,+ \text { corresponds to weak binding, and }+++ \text { corresponds to strong binding. }\end{array}$} \\
\hline
\end{tabular}

lower radioactivity uptake in the bone than the $(R)$-enantiomer. Similar differences between enantiomers were also observed in the metabolism of ${ }^{18}$ F-THK-5105 and revealed to be caused by stereospecific hepatic metabolism (24). There was a large difference in the generation of $\mathrm{M} 2$ at $10 \mathrm{~min}$ after injection between ${ }^{18} \mathrm{~F}-\mathrm{THK}-$ 5351 and ${ }^{18} \mathrm{~F}-$ THK-5451, suggesting that it is possible that the rapid metabolism to M2 stimulates the elimination of ${ }^{18} \mathrm{~F}-\mathrm{THK}-5351$ from the mouse body.

In contrast to the observations in plasma, the amount of M2 was less obvious in the brain, indicating that M2 was less likely to cross the blood-brain barrier (Fig. 4). Therefore, M2 would have little effect on the quantitative analysis of the brain kinetics. However, M3 was observed in the brain to a similar extent as in plasma. This result suggests that M3 is likely to cross the blood-brain barrier and may potentially affect the quantitative analysis. Thus, it is important to clarify whether M3 is generated in human plasma or not in a human PET study.

The mechanism responsible for the defluorination of ${ }^{18} \mathrm{~F}-\mathrm{THK}-$ 5151 enantiomers was not clear, but the difference in bone accumulation seemed to be caused by the stereospecificity of some enzymatic defluorination pathways $(28,29)$. There are several (3-18 F-fluoro-2-hydroxy)-1-propoxy-containing PET tracers currently under development, and our study suggests that preparation of pure single enantiomers may produce significant improvement in their properties $(30,31)$.

In summary, ${ }^{18} \mathrm{~F}-\mathrm{THK}-5351\left({ }^{18} \mathrm{~F}-(S)-\mathrm{THK}-5151\right)$, which has both methylaminopyridine and 3-fluorohydroxypropoxyl structures, showed the most favorable properties as a tau radiotracer candidate. However, it is generally difficult to predict and conclude the clinical utility of a PET tracer only from the preclinical data. In the case of ${ }^{18} \mathrm{~F}-\mathrm{THK}-5117$, which has a lower lipophilicity than ${ }^{18} \mathrm{~F}-\mathrm{THK}-5105$, the tracer showed faster brain kinetics in both mice and humans than ${ }^{18} \mathrm{~F}-\mathrm{THK}-5105$ (Table 4), leading to highercontrast PET images than ${ }^{18} \mathrm{~F}-\mathrm{THK}-5105$. Because of the same reason, ${ }^{18} \mathrm{~F}-\mathrm{THK}-5351$ could exhibit faster brain kinetics and produce better-contrast PET images than ${ }^{18} \mathrm{~F}-\mathrm{THK}-5117$. Actually, preliminary PET study in humans demonstrated faster brain kinetics of ${ }^{18} \mathrm{~F}-\mathrm{THK}-5351$ than ${ }^{18} \mathrm{~F}-\mathrm{THK}-5117$ (Table 4) (32). However, such approach for optimization might not resolve an issue of off-target binding to the basal ganglia commonly observed in both ${ }^{18} \mathrm{~F}-\mathrm{THK}-5105$ and ${ }^{18} \mathrm{~F}-\mathrm{THK}-5117$. Further optimization study to address the issue of off-target binding through a different approach may be necessary in the future.

\section{CONCLUSION}

This study revealed the influence of the ${ }^{18} \mathrm{~F}$-labeled side chain on the characteristics of brain imaging radiotracers. ${ }^{18} \mathrm{~F}-\mathrm{THK}-5351$ was selected as the most promising candidate and is currently under clinical evaluation for its utility as an AD tau PET radiotracer.

\section{DISCLOSURE}

The costs of publication of this article were defrayed in part by the payment of page charges. Therefore, and solely to indicate this fact, this article is hereby marked "advertisement" in accordance with 18 USC section 1734. This study was supported by GE Healthcare; CLINO Co. Ltd.; Sumitomo Electric Industries, Ltd.; Group CSR Foundation; a grant-in-aid for Scientific Research (B) (25293259); a grant-in-aid for Scientific Research on Innovative Areas (Brain Protein Aging and Dementia Control) (26117003) from MEXT; the Industrial Technology Research grant program of the NEDO in Japan (09E51025a); and Health and Labor Sciences Research grants from the Ministry of Health, Labor, and Welfare of Japan. No other potential conflict of interest relevant to this article was reported.

\section{ACKNOWLEDGMENTS}

We thank the staff at Cyclotron and Radioisotope Center of Tohoku University for operation of the HM-12 cyclotron.

\section{REFERENCES}

1. Serrano-Pozo A, Frosch MP, Masliah E, Hyman BT. Neuropathological alterations in Alzheimer disease. Cold Spring Harb Perspect Med. 2011;1:a006189.

2. Masters CL, Cappai R, Barnham KJ, Villemagne VL. Molecular mechanisms for Alzheimer's disease: implications for neuroimaging and therapeutics. J Neurochem. 2006;97:1700-1725.

3. Goedert M, Spillantini MC, Rutherford D, Crowther RA. Multiple isoforms of human microtubule-associated protein tau: sequences and localization in neurofibrillary tangles of Alzheimer's disease. Neuron. 1989;3:519-526.

4. Cohen TJ, Guo JL, Hurtado DE, et al. The acetylation of tau inhibits its function and promotes pathological tau aggregation. Nat Commun. 2011;2:252.

5. Hanger DP, Anderton BH, Noble W. Tau phosphorylation: the therapeutic challenge for neurodegenerative disease. Trends Mol Med. 2009;15:112-119.

6. Jack CR, Knopman DS, Jagust WJ, et al. Tracking pathophysiological processes in Alzheimer's disease: an updated hypothetical model of dynamic biomarkers. Lancet Neurol. 2013;12:207-216. 
7. Svedberg MM, Rahman O, Hall H. Preclinical studies of potential amyloid binding PET/SPECT ligands in Alzheimer's disease. Nucl Med Biol. 2012;39:484-501.

8. Zwan MD, Okamura N, Fodero-Tavoletti MT, et al. Voyage au bout de la nuit: A $\beta$ and tau imaging in dementias. Q J Nucl Med Mol Imaging. 2014;58:398-412.

9. Villemagne VL, Fodero-Tavoletti MT, Masters CL, Rowe CC. Tau imaging: early progress and future directions. Lancet Neurol. 2015;14:114-124.

10. Okamura N, Harada R, Furumoto S, Arai H, Yanai K, Kudo Y. Tau PET imaging in Alzheimer's disease. Curr Neurol Neurosci Rep. 2014;14:500.

11. Chien DT, Bahri S, Szardenings a K, et al. Early clinical PET imaging results with the novel PHF-tau radioligand [F-18]-T807. J Alzheimers Dis. 2013;34:457-468.

12. Maruyama M, Shimada H, Suhara T, et al. Imaging of tau pathology in a tauopathy mouse model and in Alzheimer patients compared to normal controls. Neuron. 2013;79:1094-1108.

13. Okamura N, Furumoto S, Fodero-Tavoletti MT, et al. Non-invasive assessment of Alzheimer's disease neurofibrillary pathology using ${ }^{18} \mathrm{~F}-\mathrm{THK} 5105$ PET. Brain. 2014;137:1762-1771.

14. Okamura N, Suemoto T, Furumoto S, et al. Quinoline and benzimidazole derivatives: candidate probes for in vivo imaging of tau pathology in Alzheimer's disease. J Neurosci. 2005;25:10857-10862.

15. Fodero-Tavoletti MT, Okamura N, Furumoto S, et al. ${ }^{18} \mathrm{~F}-\mathrm{THK} 523$ : a novel in vivo tau imaging ligand for Alzheimer's disease. Brain. 2011;134:1089-1100.

16. Okamura N, Furumoto S, Harada R, et al. Novel ${ }^{18} \mathrm{~F}$-labeled arylquinoline derivatives for noninvasive imaging of tau pathology in Alzheimer disease. $\mathrm{J} \mathrm{Nucl}$ Med. 2013;54:1420-1427.

17. Tago T, Furumoto S, Okamura N, et al. Synthesis and preliminary evaluation of 2-arylhydroxyquinoline derivatives for tau imaging. J Labelled Comp Radiopharm. 2014;57:18-24.

18. Harada R, Okamura N, Furumoto S, et al. $\left[{ }^{18} \mathrm{~F}\right]$ THK-5117 PET for assessing the neurofibrillary pathology in Alzheimer's disease. Eur J Nucl Med Mol Imaging. 2015;42:1052-1061.

19. Villemagne VL, Furumoto S, Fodero-Tavoletti MT, et al. In vivo evaluation of a novel tau imaging tracer for Alzheimer's disease. Eur J Nucl Med Mol Imaging. 2014;41:816-826

20. Li Y, Tsui W, Rusinek H, et al. Cortical laminar binding of PET amyloid and tau tracers in Alzheimer disease. J Nucl Med. 2015;56:270-273.
21. Villemagne V, Furumoto S, Fodero-Tavoletti MT, et al. The challenges of tau imaging. Future Neurol. 2012;7:409-421.

22. Mathis CA, Wang Y, Holt DP, Huang G, Debnath ML, Klunk WE. Synthesis and evaluation of ${ }^{11} \mathrm{C}$-labeled 6-substituted 2-arylbenzothiazoles as amyloid imaging agents. J Med Chem. 2003;46:2740-2754.

23. Simonyi M, Fitos I, Visy J. Chirality of bioactive agents in protein binding storage and transport processes. Trends Pharmacol Sci. 1986;7:112-116.

24. Tago T, Furumoto S, Okamura N, et al. Preclinical evaluation of $\left[{ }^{18} \mathrm{~F}\right] \mathrm{THK}-5105$ enantiomers: effects of chirality on its effectiveness as a tau imaging radiotracer. Mol Imaging Biol. July 21, 2015 [Epub ahead of print].

25. Dishino DD, Welch M, Kilbourn M. Relationship between lipophilicity and brain extraction of C-11-labeled radiopharmaceuticals. J Nucl Med. 1983;24:1030-1038.

26. Pan J, Pourghiasian M, Hundal N, et al. 2- $\left[{ }^{18} \mathrm{~F}\right]$ fluoroethanol and $3-\left[{ }^{18} \mathrm{~F}\right]$ fluoropropanol: facile preparation, biodistribution in mice, and their application as nucleophiles in the synthesis of $\left[{ }^{18} \mathrm{~F}\right]$ fluoroalkyl aryl ester and ether PET tracers. Nucl Med Biol. 2013;40:850-857.

27. Tewson TJ, Welch M. Preparation and preliminary biodistribution of "no carrieradded" fluorine-18 fluoroethanol. J Nucl Med. 1980;21:559-564.

28. Shetty HU, Zoghbi SS, Siméon FG, et al. Radiodefluorination of 3-fluoro-5-(2(2 $\left[{ }^{18} \mathrm{~F}\right]\left(\right.$ fluoromethyl)-thiazol-4-yl)ethynyl)benzonitrile ( $\left.\left[{ }^{18} \mathrm{~F}\right] \mathrm{SP} 203\right)$, a radioligand for imaging brain metabotropic glutamate subtype-5 receptors with positron emission tomography, occurs by glutathionylation in rat brain. J Pharmacol Exp Ther. 2008;327:727-735.

29. Ryu YH, Liow J-S, Zoghbi S, et al. Disulfiram inhibits defluorination of ${ }^{18} \mathrm{~F}-$ FCWAY, reduces bone radioactivity, and enhances visualization of radioligand binding to serotonin 5-HT1A receptors in human brain. J Nucl Med. 2007;48: 1154-1161.

30. Graham TJ, Lambert R. Enantioselective radiosynthesis of positron emission tomography (PET) tracers containing fluorohydrins. J Am Chem Soc. 2014;136: 5291-5294.

31. Revunov E, Jørgensen JT, Jensen AI, et al. Automated synthesis and PET evaluation of both enantiomers of [ ${ }^{18}$ F]FMISO. Nucl Med Biol. 2015;42:413419.

32. Harada R, Okamura N, Furumoto S, et al. ${ }^{18} \mathrm{~F}-\mathrm{THK}-5351$ : a novel PET radiotracer for imaging neurofibrillary pathology in Alzheimer's disease. J Nucl Med. November 5, 2015 [Epub ahead of print]. 